ROBERT E. HALL

Stanford University

\title{
E-Capital: The Link between the Stock Market and the Labor Market in the 1990s
}

OvER THE PAST decade, new technologies based on computer software began to transform the production and distribution of goods and to form the basis of new goods in the U.S. economy. The value of the stock market rose tremendously, with many of the largest increases among firms implementing the new technologies. Figure 1 depicts this increase in relation to the replacement cost of the inventories and plant and equipment of corporations. One of the reasons for the upsurge, according to the view developed in this paper, was an increase in the value of installed physical capital thanks to an unexpected rise in the demand for capital. A more important reason was the accumulation of intangibles, demand for which increased even more rapidly. Internet companies are valued almost exclusively for their intangibles: as of November 7, 2000, Yahoo! had a value of $\$ 37$ billion but only $\$ 158$ million of physical capital.

The workers who develop and use the new technologies are mostly college graduates. Both the number of college-educated workers and their relative earnings rose remarkably in the 1990s. The ratio of dollars paid

This research was supported by the National Science Foundation under grant SOC SBR9730341 and is part of the research program on Economic Fluctuations and Growth of the National Bureau of Economic Research (NBER). I am grateful to Susan Woodward, to participants in the NBER's growth research group, and to the discussants and participants at the Brookings Panel conference for comments. Jason Cummins kindly provided data on securities values by industry. Updates, data, and related papers are available on the World Wide Web at www.stanford.edu/ rehall. 
Figure 1. Traditional Measure of Tobin's $q$ for Physical Capital, 1990-99a

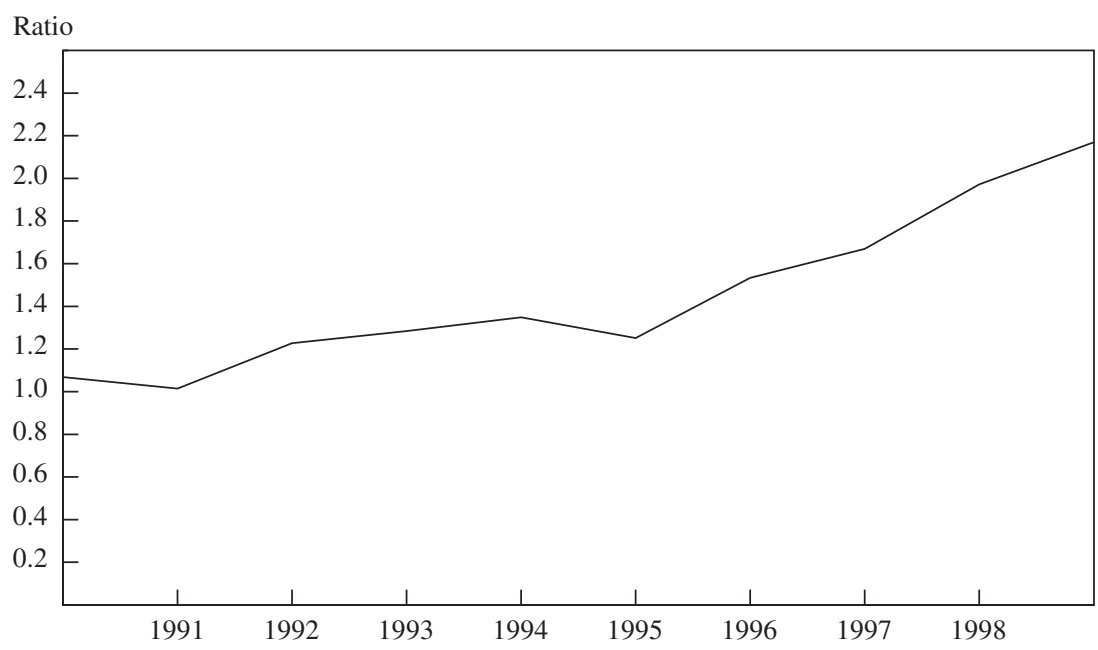

Source: Author's calculations based on data from Hall (2000).

a. Ratio of market value of nonfarm, nonfinancial corporations to replacement cost of their physical capital and inventories.

to all college graduates for their labor to dollars paid to all other workers rose from 0.61 in 1990 to 0.89 in 1998. Figure 2 shows the increase in constant-dollar earnings per worker by educational attainment from 1990 to 1998. College graduates enjoyed much larger increases than those with less education, except for the lowest education group; people with graduate training saw even greater increases.

Despite the evidence from the stock market that corporations have accumulated valuable technological resources apart from their physical capital, and despite the huge increase in demand for college graduates that derives from the new technology, productivity growth rose only a little in the 1990s. The data I use in this paper show a Solow residual, or total factor productivity growth, of 0.9 percent a year from 1990 to 1998 . This figure, which is similar to the findings of other recent studies, suggests that the idea of a technological revolution in the United States is overblown. Skeptics of the importance of new technology tend to view the high stock market valuation of U.S. corporations as an irrational bubble and note that it is unsupported by comparable improvement in current productivity or profit.

This paper pursues the argument that I have developed elsewhere that today's high stock market valuations should be taken seriously as a mea- 
Figure 2. Increases in Average Annual Real Earnings from 1990 to 1998 by Level of Education $^{\text {a }}$

Percent

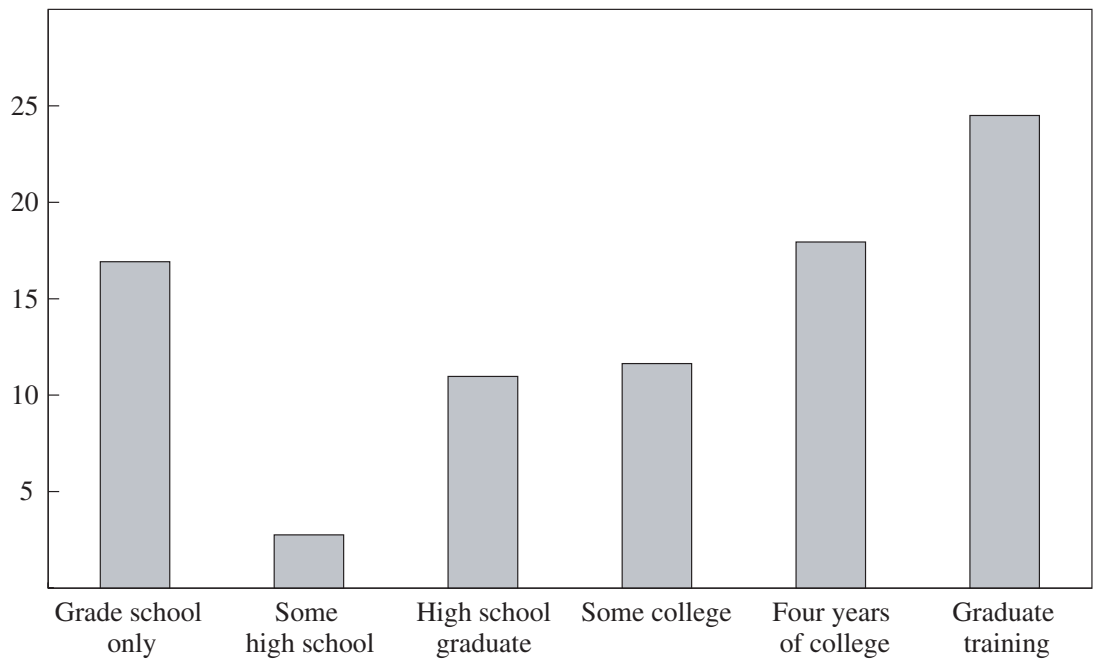

Source: Author's calculations based on data from Bureau of the Census, Current Population Survey. a. Adjusted for inflation by the implicit deflator for private GDP.

sure of the resources owned by corporations. ${ }^{1}$ I introduce a new kind of capital-e-capital - to characterize these resources. I view the production of goods and services as employing the services of e-capital along with machines, college-graduate workers (c-workers), and workers who have not graduated from college (h-workers). The technology for making e-capital is simple: c-workers by themselves make e-capital. No other factors are required. I use the standard tools of production economics to understand changes in factor intensities and factor prices, without invoking significant changes over time in the production function for goods and services.

A firm's e-capital is a body of technical and organizational know-how. Much e-capital involves the use of computers and software, but it is the business methods based on computers, not the computers themselves, that constitute e-capital. Computers count as ordinary plant and equipment. E-capital-intensive firms handle huge flows of transactions accurately 
and quickly. They employ far fewer expensive workers as problem solvers than do traditional firms, because they have developed systems to get things right the first time. Industries with high levels of e-capital relative to employment include insurance, securities brokers, communications, and equipment manufacturing. For example, online brokers such as $\mathrm{E}^{*}$ Trade prosper by substituting web servers and software for people.

E-capital is also transforming low-technology sectors such as retailing: Wal-Mart is a leading example of an e-capital-based modern enterprise. Its market capitalization of $\$ 219$ billion on November 7 was more than seven times its book value. The company has harnessed modern technology to bring about huge improvements in retail productivity and customer satisfaction.

Why did the e-capital revolution occur in the 1990s and not before? After all, computers and college degrees are hardly innovations of that decade. I explain the change in the 1990s in terms of an upsurge in saving resulting at least in part from technical progress in forming e-capital. This saving does not appear in the accounts of corporations or in the national income accounts, because the income that is saved is quickly spent on forming more e-capital in the same corporations. The evidence of this saving is indirect-it is manifested in the rising stock market.

Research on earnings trends in the labor market in the 1990s and earlier has gravitated toward the hypothesis of skill-biased technical change, particularly because other ideas, such as competition from low-wage workers in other countries, have been shown to have little role. This hypothesis-that the nature of technical change is such that it increases firms' demand for more-skilled labor-is a close relative of the view developed in this paper. The skill-bias view sees the production function as shifting over time, whereas the e-capital model explains the same shift through the increasing use of a factor left out of the skill-bias production function. Given the large increase in the fraction of workers with a college education, the dramatic rise in the relative earnings of college graduates can only be explained, in this view, by a large skill bias in the limited amount of technical change that has occurred. I calculate the amount of that change and find that it exceeds the amount that is consistent with the view that the productivity of h-workers cannot have declined during the 1990s. The explanation I offer, on the other hand, invokes capital accumulation. Increasing demand for e-capital increased the demand for college graduates. The e-capital model offers a more plausible version of the skill-bias explanation of events in the labor market. The model also incor- 
porates the rise in the stock market, a development not considered in the literature on skill bias.

The e-capital model explains the low level of measured productivity growth despite the strong evidence in the stock market and in the earnings of college graduates that a revolution is under way. The standard Solow residual treats all c-workers as working to make goods and services. Total factor inputs in the production of goods and services are overstated by the amount of the services of c-workers actually used to make e-capital. This overstatement is more than offset by the failure to include e-capital as an input in standard productivity calculations. My calculation of total factor productivity growth in goods and services using the standard framework -0.9 percent a year-overstates actual productivity growth, which is barely positive in my model. The driving force behind rising output and the rising stock market is technical progress in making e-capital, coupled with the formation of large amounts of e-capital, according to my model.

The methods used here are relentlessly nonparametric. The Solow residual is the primary tool. In addition, I test the implications of the e-capital model against the weak axiom of cost minimization-in effect, asking why e-capital was not used before 1990 even though it was practical to produce it. I also use a nonparametric approach to measure skill bias.

A related aspect of this paper is its method for specifying key parameter values. The method fails to rise even to the level of calibration, much less estimation. Instead I choose values of adjustment costs and other parameters in such a way that the resulting story seems to make sense.

Erik Brynjolfsson and Shinkyu Yang provide supporting evidence about e-capital. ${ }^{2}$ They demonstrate that firms with higher levels of observed investment in information technology (IT) - a likely correlate of e-capital-have much higher valuations than do other firms. In the framework of this paper, their results suggest that the typical IT firm possesses about nine dollars of e-capital for each dollar of observed IT capital.

The research approach adopted in this paper is to see whether a unified explanation can be found for the dramatic events of the 1990s. I do not claim that this explanation is superior to others. I do not believe that any research has answered the question of whether the stock market has behaved rationally, with respect to either its low values from 1973 to 1989

2. Brynjolfsson and Yang (1999). 
or its high values in the 1960s and the 1990s. ${ }^{3}$ Rather, I develop a complete account of some important events of the 1990s, under the assumption of market rationality, that may persuade some readers that the assumption is not as farfetched as they thought.

The paper does not tackle a full general-equilibrium consideration of the events of the 1990s. It restricts its formal analysis to that of production. The other important part of a model with one kind of output is consumption and saving, where saving includes the inflow of capital from abroad. According to the e-capital view, the U.S. economy did a huge amount of saving in the 1990s, which would be revealed in a new set of national income and product accounts that included the production of e-capital and the income earned from that production. It is a challenge to consumption theory to explain why the saving occurred. That challenge is not taken up in this paper.

\section{The Stock Market}

A premise of this paper is the rationality of the stock market, or, more precisely, of securities markets generally. The value of all securities that are claims on corporations reveals the value of the business assets of those corporations. In an irrational market, securities might be worth more than the underlying assets-a suspicion today given the facts in figure 1 for recent years. Or they might be worth less-a suspicion supported by the late 1970s and early 1980s, when the stock market valued capital at about 50 cents on the dollar. ${ }^{4}$ Two tasks face the researcher who invokes the hypothesis of stock market rationality: understanding the high valuations of the 1990s and understanding the low valuations of the 1970s and 1980s. This paper undertakes only the first task.

Valuation deals with four different measures of value, all of which should be the same, according to received principles:

- the observed market value of the securities of corporations;

- the present value of future receipts of the owners of those securities;

3. See Hall (2000) for a discussion of Bond and Cummins's rejection of rationality in the last issue of this series.

4. Brainard, Shoven, and Weiss (1980). 
- the present value of the nonfinancial cash flows of corporations; and

- the market values of the various business assets of corporations.

The relation between the first two measures, the market prices of securities and their future payouts, has been the subject of far too much research in finance to begin to cite. A fair summary of this research is that there has been no definitive finding of departure from the valuation principle: that the price of a security is the present value of its future returns. It is true that the values of most stocks today are far above the present value of any reasonable prediction of future dividends. But formal testing also has to consider the terminal value, when a shareholder liquidates a position, and the present value of liquidation easily makes up for the shortfall in the value of dividends. Tests have relatively low statistical power as a result. The absence of definitive evidence of the failure of the valuation principle is not, however, strong evidence in favor of rationality.

The third measure of value, the present discounted value of nonfinancial corporate cash flows, is called intrinsic value. Research on this measure has been sparser - the work of William Brainard, John Shoven, and Laurence Weiss remains the most prominent. ${ }^{5}$ Their findings are supported by the recent work of Steven Bond and Jason Cummins. ${ }^{6}$ Both studies find that intrinsic value in all years roughly equals the estimated replacement cost of plant and equipment. There is little room for intangibles in the 1990s (as shown by Bond and Cummins), and the low stock market in 1980 is a deep mystery (as Brainard, Shoven, and Weiss demonstrate).

The replacement cost of plant and equipment differs from its market value when there are adjustment costs. In times of rapid growth, the price of installed capital will exceed its replacement cost. Tobin's $q$-the ratio of the two values-will exceed one. I estimate Tobin's $q$ for U.S. corporations in this paper and find that its rise in the 1990s is an important but not the dominant explanation of the rise in securities values.

There are huge differences between the internal cash flows of corporations and the cash paid out to securities owners. ${ }^{7}$ In the late 1970 s and early 1980s when the stock market was depressed, securities owners were actually paying cash in to corporations, in contrast to normal years, when

5. Brainard, Shoven, and Weiss (1980).

6. Bond and Cummins (2000).

7. See Hall (2000) for data. 
cash moves from corporations into the hands of securities owners. If shareholders thought that corporations were dissipating value in a way not captured by projections of cash flow, the low value of the stock market in that period might make sense. Similarly, shareholders in the 1990s may have thought that the activities of corporations were adding to later payouts in a way not captured by cash-flow projections. Because there is a lot of room for differences between the cash flows projected by Brainard, Shoven, and Weiss and their followers, and cash flows received by securities owners, the gap between the value of securities and intrinsic value can be large. The question is whether it can be as negative as it was in 1980 or as positive as it was in 1999 without invoking market irrationality.

\section{A Four-Factor Model}

The model that I develop in this section entertains the hypothesis that securities markets reveal the approximate value of the business assets of corporations. These assets are physical capital and e-capital. (I will add inventories in the application but will not clutter the development of the model with them.) The model hypothesizes adjustment costs for both types of capital, so that market value departs from replacement cost. As noted in the introduction, the model distinguishes two kinds of workers: c-workers, who have graduated from college, and h-workers, who have not. The acquisition price of e-capital is determined by the wages of c-workers and their productivity in making e-capital.

\section{Technology and Productivity Growth}

Define the following notation:

$e_{t}=$ quantity of e-capital

$k_{t}=$ quantity of physical capital (plant and equipment)

$c_{t}=$ labor input of c-workers (college graduates)

$h_{t}=$ labor input of h-workers (not college graduates)

$y_{t}=$ output

$r_{t}^{e}=$ rental price of e-capital

$r_{t}^{k}=$ rental price of physical capital

$w_{t}^{c}=$ wage rate for $\mathrm{c}$-workers

$w_{t}^{h}=$ wage rate for h-workers 


$$
\begin{aligned}
p_{t}^{y}= & \text { price of output } \\
p_{t}^{e}= & \text { price of e-capital } \\
p_{t}^{k}= & \text { price of physical capital, and } \\
A_{t}= & \text { an index of Hicks-neutral, or output-augmenting, technical } \\
& \text { change. }
\end{aligned}
$$

I assume constant returns to scale. Let the technology for producing output $y$ be

$$
y_{t}=A_{t} f_{i}\left(e_{t}, k_{t}, c_{t}^{y}, h_{t}\right) \text {. }
$$

Here $c_{t}^{y}$ is the amount of c-labor used as an input to goods and services production. I assume constant returns (but not competition) and perform the Solow-Divisia exercise on the production function. That is, I take the time derivatives of both sides, replace the derivatives of the production function with the corresponding factor prices, and approximate the time derivatives of the form $\dot{x} / x$ with the discrete approximation $\Delta \ln x$ :

$$
\begin{aligned}
\Delta \ln y_{t}= & \Delta \ln A_{t}+\frac{r_{t}^{e} e_{t}}{C_{t}} \Delta \ln e_{t}+\frac{r_{t}^{k} k_{t}}{C_{t}} \Delta \ln k_{t} \\
& +\frac{w_{t}^{c} c_{t}^{y}}{C_{t}} \Delta \ln c_{t}^{y}+\frac{w_{t}^{h} h_{t}}{C_{t}} \Delta \ln h_{t} .
\end{aligned}
$$

Here $C_{t}$ is total cost:

$$
C_{t}=r_{t}^{e} e_{t}+r_{t}^{k} k_{t}+w_{t}^{c} c_{t}^{y}+w_{t}^{h} h_{t}
$$

The observed rate of change of output is the rate of productivity growth (the Solow residual, $\Delta \log A_{t}$, which measures the shift of the production function $)^{8}$ plus the weighted average of the rates of change of the factor inputs, with cost shares serving as weights. The use of cost shares avoids Solow's original assumption of competition but requires explicit mea-

8. The standard formula for the Solow residual appears to break down when there is a zero level of an input. This is an illusion associated with dividing and multiplying by the input level in the derivation. The underlying logic of the Solow residual rests on a linear approximation to the production function, which encounters no problems when an input is at zero. In that case, the contribution of a factor needs to be calculated as, for example, $\frac{r^{k} \Delta k}{p^{q} q}$. 
surement of the rental price of capital. ${ }^{9}$ I actually measure the shares as the equally weighted average of the shares at times $t-1$ and $t$ : a measure called, by its modest inventors, the superlative index of total factor input. ${ }^{10}$

\section{Adjustment Costs}

One reason why the stock market rose in the 1990s was unexpected growth in demand for both physical capital and e-capital. For the theory of investment in physical capital I adopt the standard neoclassical investment model with adjustment costs, as formalized by Andrew Abel and others. ${ }^{11}$ This model combines Dale Jorgenson's theory of the demand for installed capital with James Tobin's theory of the supply of installed capital. The model stands as the accepted modern paradigm of investment with smooth adjustment. I define $q_{t}^{k}$ as Tobin's $q$ for physical capital, the ratio of the price of installed capital to the price of new capital goods. I take the adjustment technology to be quadratic with constant returns to scale, and so the first-order condition for the supply of installed capital is

$$
\alpha_{t}^{k} \frac{k_{t}-k_{t-1}}{k_{t-1}}=q_{t}^{k}-1 .
$$

When capital is stationary, $q_{t}^{k}$ takes its equilibrium value of 1 . When rising demand for capital results in growth of the capital stock, the value of installed capital rises above the price of capital goods by an amount proportional to the rate of growth of the capital stock. Equation (4) is the supply function for the internal capital market.

The parameter $\alpha_{t}^{k}$ measures adjustment costs. I add the time subscript to account for the asymmetry of the installation process - it is much cheaper to install capital than to remove it.

My specification of adjustment costs for e-capital differs in one respect from the model just described. In equation (4) the denominator in the fraction is a scaling variable that results in an adjustment technology with constant returns to scale. In the case of e-capital, it would not make sense to scale by the earlier value of the stock of e-capital, because in some years

9. See Hall (1990).

10. See, for example, Caves, Christensen, and Diewert (1982).

11. Abel (1979). 
(before 1990) the stock of e-capital is zero. Consequently, I scale adjustment costs for e-capital by physical capital:

$$
\alpha_{t}^{e} \frac{e_{t}-e_{t-1}}{k_{t-1}}=q_{t}^{e}-1
$$

Otherwise the setup for e-capital is the same as for physical capital, with an installed price ratio $q_{t}^{e}$ and an adjustment parameter $\alpha_{t}^{e}$.

\section{Measuring Capital and the Price of Installed Capital}

The flow of purchases of new plant and equipment, $x_{t}$, is observable. I calculate the stock of capital from the perpetual inventory equation,

$$
k_{t+1}=\left(1-\delta^{k}\right)\left[k_{t}+x_{t}-\frac{\alpha^{k}}{2} \frac{\left(k_{t+1}-k_{t}\right)^{2}}{k_{t}}\right],
$$

where $\delta^{k}$ is the rate of deterioration of physical capital. Note that equation (6) is a quadratic that must be solved for the capital stock. Then I calculate the price of installed capital by solving equation (4):

$$
q_{t}^{k}=\alpha_{t}^{k} \frac{k_{t}-k_{t-1}}{k_{t-1}}+1 .
$$

The market value of physical capital is

$$
v_{t}^{k}=q_{t}^{k} p_{t}^{k} k_{t} .
$$

For e-capital I adapt the measurement approach in my previous paper on this topic. ${ }^{12}$ Flows of investment in e-capital are invisible. But the market value of e-capital is the difference between the observed total market value of firms and the market value of their physical capital:

$$
v_{t}^{e}=v_{t}-v_{t}^{k} .
$$

I assume that one year of work by a c-worker creates $(1+\lambda)^{t}$ units of e-capital—no other factors are required to make e-capital. The variable $\lambda$ is the rate of growth of productivity in the creation of e-capital. An imme-

12. Hall (2000). 
diate implication is that the price paid at the end of period $t$ to form a unit of uninstalled e-capital starting in period $t+1$ is $p_{t}^{e}=(1+\lambda)^{-t} w_{t}^{c}$.

Now consider the supply condition for installed e-capital, equation (5), and the value relation,

$$
v_{t}^{e}=q_{t}^{e} p_{t}^{e} e_{t}=v_{t}-v_{t}^{k} .
$$

These are two equations in two unknowns, $e_{t}$ and $q_{t}^{e}$. Figure 3 describes their solution. Equation (10) is a downward-sloping hyperbola, whereas marginal adjustment cost, equation (5), is an upward-sloping line. The intersection occurs at the inferred quantity of e-capital, $e_{t}$, and its value in relation to acquisition cost, $q^{e}$.

Notice that the position of the marginal adjustment cost schedule depends on the lagged value of e-capital. Hence the procedure makes the current value of e-capital a function of the lagged value. The procedure defines a recursion for calculating e-capital. My earlier paper shows that the recursion is quite stable. ${ }^{13}$ Although it requires an assumed initial value, the calculated values for later years are not sensitive to the initial value. I use an initial value of zero in my calculations.

\section{Rental Prices for Physical and E-Capital}

The rental price for installed physical capital is

$$
r_{t}^{k}=\frac{1-\tau z}{1-\tau}\left[q_{t}^{k} p_{t}^{k}-\frac{1-\delta^{k}}{1+r_{t}^{f, k}} E_{t}\left(q_{t+1}^{k} p_{t+1}^{k}\right)\right] .
$$

Here $r_{t}^{f, k}$ is the risk-adjusted interest rate for physical capital, $\tau$ is the corporate tax rate, and $z$ is the present discounted value of tax deductions associated with physical capital. ${ }^{14}$ To evaluate the expectation of the future market value of installed capital, I assume, first, that the future price of uninstalled capital, $p_{t+1}^{k}$, is approximately known at time $t$, and that $q$ returns to its normal value of one at a rate $\rho$. Reversion of $q$ to its mean is an implication of almost any general-equilibrium model. ${ }^{15}$ Thus I measure the rental price of physical capital as 
Figure 3. Price and Quantity of E-Capital in Equilibrium

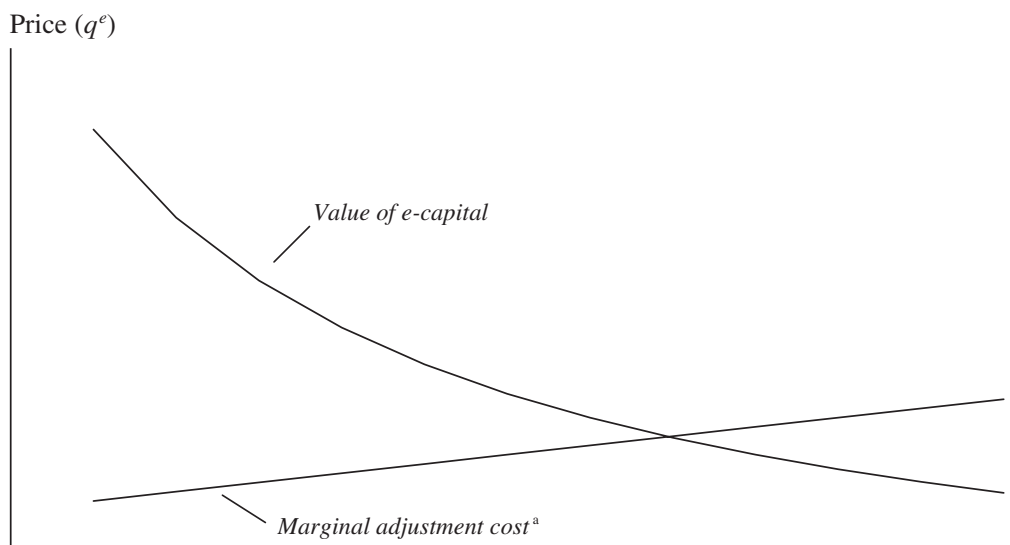

Quantity $(e)$

Source: Author's calculations based on equations (5) and (10) in the text.

a. Given e-capital in the previous period.

$$
r_{t}^{k}=\frac{1-\tau z}{1-\tau}\left\{q_{t}^{k} p_{t}^{k}-\frac{1-\delta^{k}}{1+r_{t}^{f, k}}\left[1+(1-\rho)\left(q_{t}^{k}-1\right)\right] p_{t+1}^{k}\right\} .
$$

Similarly, I measure the rental price of installed e-capital as

$$
r_{t}^{e}=q_{t}^{e} p_{t}^{e}-\frac{1-\delta^{e}}{1+r_{t}^{f, e}}\left[1+(1-\rho)\left(q_{t}^{e}-1\right)\right] p_{t+1}^{e} .
$$

Here $r_{t}^{f, e}$ is the financial return required by the market, adjusted for the risk associated with holding a unit of e-capital during period $t$. The variable $\delta^{e}$ is the rate of deterioration of e-capital. In this formula I assume that the costs of producing e-capital are deductible for tax purposes as they are incurred.

\section{Allocating C-Workers between the Two Sectors}

I assume that the adjustment costs for e-capital take the form of work effort on the part of c-workers. Then employment of c-workers making and installing e-capital is 


$$
c_{t}^{e}=e_{t}-\left(1-\delta^{e}\right) e_{t-1}+\frac{\alpha_{t}^{e}}{2}\left(\frac{e_{t}-e_{t-1}}{k_{t-1}}\right)^{2} .
$$

The remainder, $c_{t}^{q},=c_{t}-c_{t}^{e}$, are employed at producing goods and services.

The model developed in this section enables the calculation of all of the quantities and prices needed to tell the e-capital story. The values of the two kinds of capital and their installed prices account, by construction, for the level of securities prices. The quantities of factors used in the production of goods and services enable the calculation of productivity and the testing of the story within production theory.

\section{Parameter Values}

Table 1 shows the values of the parameters I use in the subsequent calculations. As noted earlier, I make no pretense of formally estimating the parameters and draw on the existing literature only in the most general way. I candidly admit that I have chosen the parameter values to achieve what seems to me the most reasonable version of the e-capital story.

My earlier paper discusses evidence on the value of the adjustment parameter for plant and equipment, $\alpha^{k} .{ }^{16}$ One body of research on adjustment costs and speeds infers Tobin's $q$ from securities values, whereas a second body uses other methods. The value used here is consistent with some research in the second category. All research that does form $q$ from securities prices finds slower adjustment by far than this value implies. I believe that such slow adjustment rates, and correspondingly high levels of adjustment costs, are the result of severe specification errors in the estimation equations. Measures of $q$ from securities values are completely unsuccessful in isolating the actual value of installed plant and equipment; the measures are contaminated by the value of intangibles. I assign a value for the downward adjustment cost for e-capital that is ten times the upward cost, to capture the near irreversibility of investment.

\section{Data}

My aim is to consider the private economy exclusive of agriculture and households. It is not possible to obtain all the necessary data for

16. Hall (2000). 
Table 1. Assumed Parameter Values in the E-Capital Model

\begin{tabular}{llr}
\hline Parameter & \multicolumn{1}{c}{ Interpretation } & Value \\
\hline$\alpha^{\mathrm{k}}$ & Upward adjustment cost for physical capital & 3.00 \\
$\alpha^{\mathrm{e}}$ & Upward adjustment cost for e-capital & 3.00 \\
& Downward adjustment cost for e-capital & 30.00 \\
$\delta^{\mathrm{k}}$ & Deterioration rate for physical capital, per year & 0.10 \\
$\delta^{\mathrm{e}}$ & Deterioration rate for e-capital, per year & 0.06 \\
$\lambda$ & Rate of growth of productivity in creating e-capital & 0.03 \\
$\tau$ & Corporate tax rate & 0.34 \\
$z$ & Present value of tax deductions for physical capital & 0.72 \\
$\rho$ & Rate of mean reversion of $q^{e}$, per year & 0.20 \\
\hline
\end{tabular}

exactly this definition. Data for output are GDP originating in private nonfarm, nonhousing businesses. Data for investment in physical capital are the sum of private fixed investment in industrial structures, commercial structures, mining construction, and nonresidential equipment and software, less tractors and agricultural equipment.

The market value of securities of nonfarm, nonfinancial corporations is taken from my previous paper. ${ }^{17}$ I measure e-capital for this sector only, which differs from the coverage of the other data by excluding noncorporate businesses and financial corporations. From the value of securities I subtract the value of inventories, estimated as private nonfarm inventories multiplied by the ratio of physical capital for nonfarm, nonfinancial corporations to capital calculated from the series described above. I also subtract the value of capital for nonfarm, nonfinancial corporations as the product of their calculated capital, the deflator for the investment series, and my estimate of $q$ for physical capital.

Data for earnings by education are from the Census Bureau's Current Population Survey, tables P-28 and P-29 for 1986-90. I rescaled the data for compensation and hours to levels for the private nonfarm economy from the national income and product accounts. The calculation assumes that annual hours per worker are roughly the same for c-workers and $\mathrm{h}$-workers and that the mix of the two types of workers is the same in the private nonfarm economy as in the entire economy covered by the Current Population Survey. 


\section{Results}

Figure 4 shows the value of $q^{k}$ that results from applying equation (7) with a value for the adjustment coefficient of 3 at annual rates. The capital stock grew throughout the period, so that $q$ was always above 1 . Growth increased after 1993, resulting in rising values of $q$.

Figure 5 shows the calculated quantity of e-capital over the period, and figure 6 shows the corresponding values of $q^{e}$. Figure 7 decomposes the rise in the stock market in the 1990s into the various components in the measurement system of this paper. At the bottom is the movement of inventories, a small part of the story. The next line up adds the value of plant and equipment without including changes associated with $q^{k}$. The line just above that adds the effect of rising scarcity of plant and equipment recorded by $q^{k}$. The next-to-last line adds e-capital without $q^{e}$; this is the single largest factor in the rise of the market. The top line, the actual value of the market, includes the considerable extra effect of the rising scarcity value of e-capital.

Almost every other discussion of the rise of the stock market in the 1990s has a completely different character. These discussions attribute the rise to lower discount rates resulting from lower equity premiums, more widespread ownership of stock, and the like. Is there a conflict between the two approaches to understanding the stock market?

In general equilibrium the value of the stock market obeys two principles. It is simultaneously the value of what corporations own (disregarding debt for the moment) and the present value of receipts anticipated by shareholders. The decomposition of value in figure 7 tracks the first principle. I have not tried here to measure any present values, because they are difficult and unnecessary for my purposes. It is important to understand that there is nothing causal about figure 7 . It should not be read as saying that, because corporations happened to invest in e-capital, the stock market rose. The exogenous forces accounting for the events displayed in the figure are complex. They include the willingness of U.S. residents to save enough to invest in huge quantities of plant, equipment, and e-capital (with help from abroad), and possibly changes in the equity premium. ${ }^{18}$

18. For an example of full general-equilibrium modeling of these issues, see Abel (1999). 
Figure 4. Estimated $q$ for Physical Capital, 1990-99

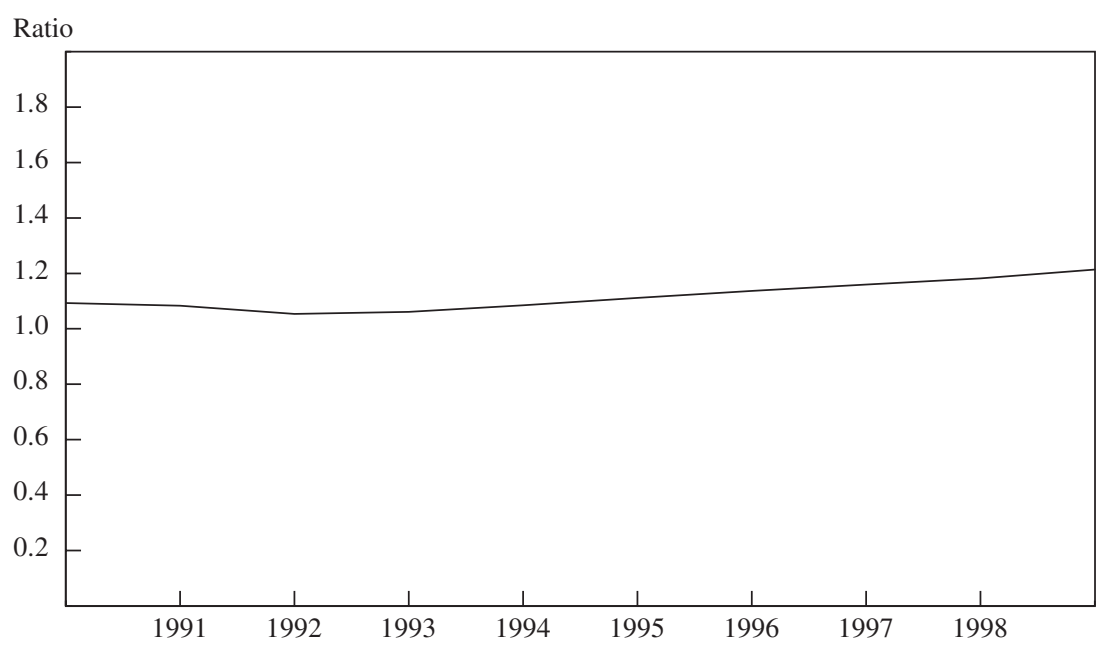

Source: Author's calculations based on equation (7) in the text.

Figure 5. Estimated Stock of E-Capital, 1990-99

Trillions of dollars

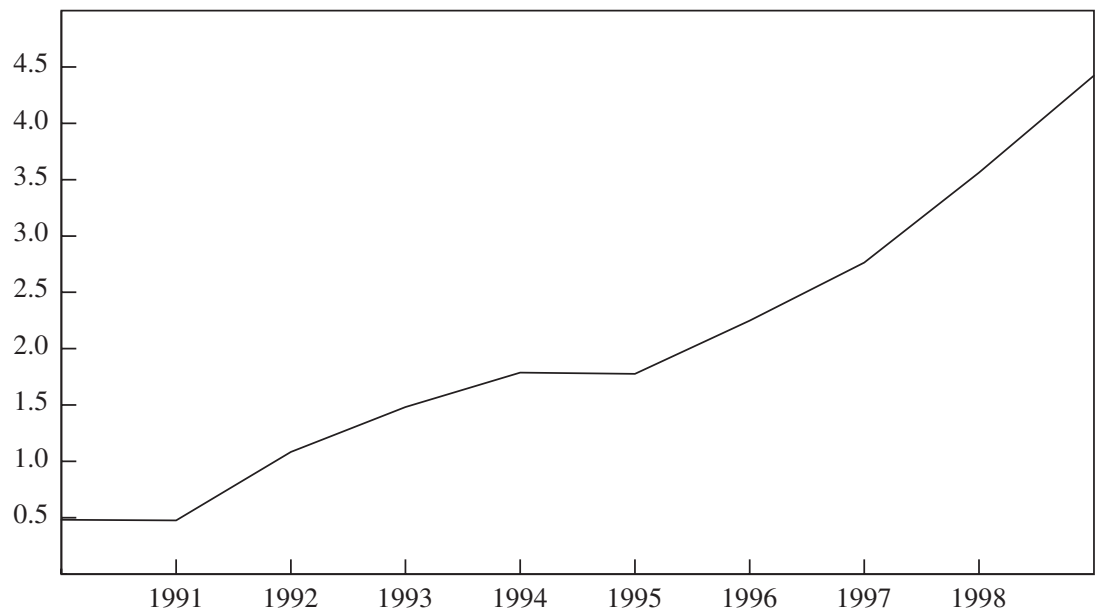

Source: Author's calculations based on equations (5) and (10) in the text. 
Figure 6. Estimated $q$ for E-Capital, 1990-99

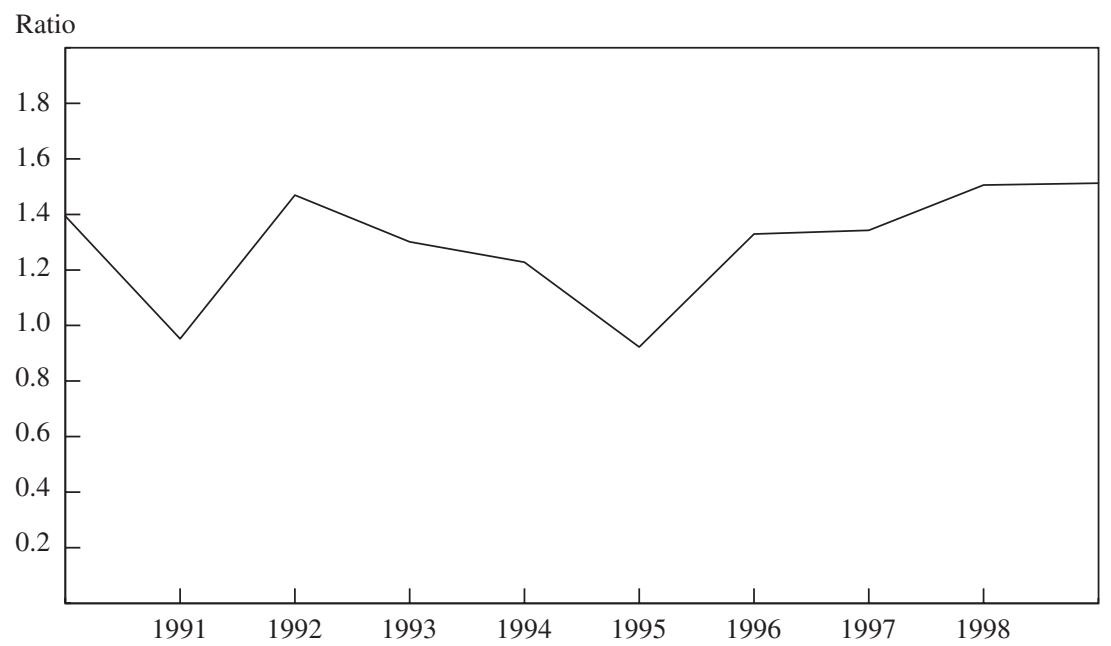

Source: Author's calculations based on equations (5) and (10) in the text.

\section{Figure 7. Accounting for E-Capital in Stock Market Capitalization, 1990-99a}

Trillions of dollars

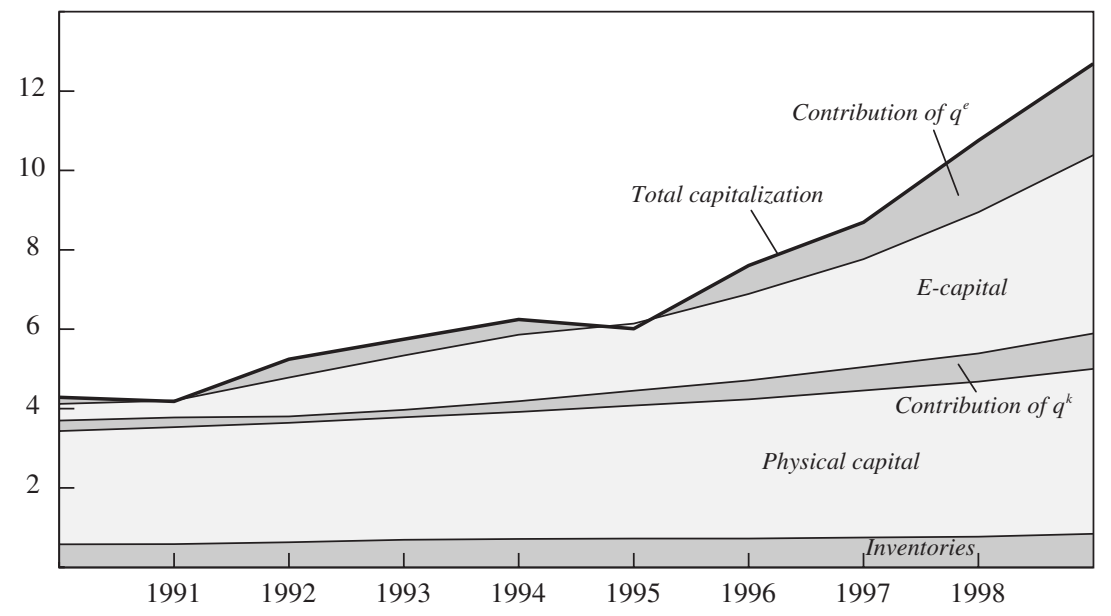

Source: Author's calculations based on data from Bureau of Economic Analysis, National Income and Product Accounts. a. Market capitalization of the stock market plus the estimated market value of other claims as described in Hall (2000). 


\section{Productivity Calculations}

Many observers appear to believe that the modest acceleration of productivity in the 1990s is inconsistent with the enormous increase in stock market valuations. How can economic changes that add less than a percentage point to productivity growth result in a growth of securities values to more than double the value of inventories, plant, and equipment? The calculations in this section suggest that there is no contradiction. Productivity growth is hard to change. Even the massive transformation of the economy in the e-capital story does not imply much change in productivity growth. That transformation was mostly the result of saving and capital accumulation, not productivity growth, according to the e-capital story.

Table 2 shows two productivity calculations for the goods and services sector. The table's upper panel applies the ideas of this paper by adding e-capital as an input and removing the fraction of c-workers employed in the production of e-capital. The lower panel reports standard calculations. The calculations are made from discrete changes from 1990 to 1998 without using the intervening data. Spencer Star and I have demonstrated that almost nothing is gained from using annual changes rather than changes over longer periods. ${ }^{19}$

The upper panel of table 2 shows that the input of e-capital rose substantially (this measurement uses the method discussed in footnote 8), although the average weight given to e-capital is only 9 percent. Employment of c-workers grew about 1 percent over the period, and the share given to them here is only 23.9 percent, because 49 percent of c-workers were not employed in this sector but rather were making e-capital. Just under half of the cost of goods and services comes from h-workers. Productivity remained unchanged over the eight years.

In the lower panel e-capital does not play a role, and all c-workers are treated as employed in the goods and services sector. Because the addition of more c-workers does not completely offset the removal of e-capital, the growth of total factor inputs and of the productivity residual is somewhat higher, at 0.9 percent annually. ${ }^{20}$

19. Star and Hall (1976).

20. This is close to the value reported by Jorgenson and Stiroh (2000). 
Table 2. Calculating Productivity with and without E-Capital, 1990-98 ${ }^{\text {a }}$

Percent

\begin{tabular}{lccccc}
\hline Item & E-capital & $\begin{array}{c}\text { Physical } \\
\text { capital }\end{array}$ & $\begin{array}{c}\text { College } \\
\text { graduates }\end{array}$ & $\begin{array}{c}\text { Non-college } \\
\text { graduates }\end{array}$ & Change \\
\hline With e-capital & & & & & \\
Input change, 1990-98 & $\ldots$ & 35.4 & 1.1 & 35.4 & \\
Input weight & 9.0 & 23.5 & 23.9 & 48.1 & \\
Input contribution & 15.0 & 8.3 & 0.3 & 4.2 & 27.7 \\
Output & & & & & 28.0 \\
Residual & & & & & 0.3 \\
Productivity & & & & & 0.0 \\
Without e-capital & & 35.4 & 28.3 & 35.4 & \\
Input change, 1990-98 & $\ldots$ & 21.9 & 33.2 & 44.9 & \\
Input weight & & 7.8 & 9.4 & 3.9 & 21.0 \\
Input contribution & & & & & 28.0 \\
Output & & & & & 0.9 \\
Residual & & & & & 0.9 \\
Productivity & & & & & \\
\hline
\end{tabular}

Source: Author's calculations based on data from Bureau of Economic Analysis, National Income and Product Accounts.

a. Figures may not sum to totals because of rounding.

b. Expressed as an annual rate.

\section{Consistency with Production Theory}

Is the e-capital story consistent with standard production theory? A basic property of the theory is the weak axiom of cost minimization (WACM). ${ }^{21}$ The WACM test operates on normalized data, showing the packages of inputs needed to produce one unit of output in each of two years, here 1990 and 1998. The unit of output is larger in the later year to account for Hicks-neutral productivity growth during the intervening years. Thus the 1990 input package did produce one unit of output in 1990 and could have produced one bigger unit of output in 1998. Similarly, the 1998 input package could have produced one unit in 1990 and did produce one unit in 1998. The WACM test asks two intuitive questions:

- Could the economy have saved money in 1990 by producing a unit of output with the 1998 input package instead of the actual 1990 input package? In other words, does the 1998 input package cost less at 1990 factor prices than the 1990 input package? If so, something is wrong. 
- Could the economy have saved money in 1998 by producing a unit of output with the 1990 input package instead of the actual 1998 input package? In other words, does the 1990 input package cost less at 1998 factor prices than the 1998 input package? If so, something is wrong.

Of the two tests, the first is the more important for evaluating the e-capital story. E-capital was available in 1990; the story explains the small amount that was used by the high relative price of e-capital back then. Table 3 applies the WACM to data for the beginning and ending years of my analysis, 1990 and 1998.

The inputs in the first two rows are normalized by the Divisia index of input, to adjust for output and productivity growth. The goods and services sector used much more e-capital in 1998 than in 1990, somewhat more machines, about the same c-labor, and rather less h-labor. Relative factor prices moved in accordance with these changes in factor intensities. In particular, the relative price of c-labor rose dramatically.

Table 3 shows that the e-capital view of the 1990s does satisfy the basic rationality condition of production economics. The essential question is why the economy waited until the 1990s to begin to accumulate e-capital. The e-capital view would fail if the 1998 factor input bundle-which contains quite a bit of e-capital services-could have produced the 1990 level of output more cheaply (at 1990 prices) than the bundle actually chosen. The answer, in the middle panel of table 3, is that the 1990 input bundle was actually cheaper. The adoption of e-capital during the 1990s occurred because e-capital substituted for expensive c-labor, and e-capital's price relative to c-labor was falling at 3 percent a year. For the same reason, it would not have been economical to use the 1990 input bundle to produce the 1998 level of output.

\section{Sensitivity Analysis}

The previous discussion has developed three criteria for deciding whether the e-capital story is plausible: Does it imply nonnegative total factor productivity growth for goods and services, counting e-capital as an input? Does it pass the WACM test in 1990? And does it pass the WACM test in 1998 ?

The model includes five parameters whose values are a matter of guesswork: the cost-of-adjustment parameter for plant and equipment, $\alpha^{k}$; the 
Table 3. Calculations for the Weak Axiom of Cost Minimization Test

Billions of 1998 dollars, except where noted otherwise

\begin{tabular}{lccccc}
\hline Item & E-capital & $\begin{array}{c}\text { Physical } \\
\text { capital }\end{array}$ & $\begin{array}{c}\text { College } \\
\text { graduates }\end{array}$ & $\begin{array}{c}\text { Non-college } \\
\text { graduates }\end{array}$ & Total \\
\hline Inputs, $1990^{\mathrm{a}}$ & 482 & 3,781 & 902 & 1,966 & \\
${\text { Inputs, } 1998^{\mathrm{a}}}^{\text {Prices, } 1990^{\mathrm{b}}}$ & 2,701 & 4,083 & 701 & 1,625 & \\
Prices, $1998^{\mathrm{b}}$ & 0.180 & 0.193 & 0.693 & 0.835 & \\
& 0.212 & 0.215 & 1.000 & 1.000 &
\end{tabular}

First WACM test: is a unit of 1990 output cheaper to produce with 1990 than with 1998 inputs?

\begin{tabular}{lccccc}
$\begin{array}{l}\text { Cost of } 1990 \text { output at } \\
\quad 1990 \text { prices }\end{array}$ & 87 & 730 & 625 & 1,641 & 3,083 \\
$\begin{array}{l}\text { Cost of } 1990 \text { output at } \\
\quad 1998 \text { prices }\end{array}$ & 486 & 789 & 486 & 1,356 & 3,117 \\
$\begin{array}{l}\text { Difference } \\
\begin{array}{l}\text { Second WACM test: is } \text { a } \\
\text { 1990 inputs? }\end{array}\end{array}$ & -399 & -58 & 139 & 285 & -34 \\
$\begin{array}{l}\text { Cost of } 1998 \text { output at } \\
\quad 1990 \text { prices }\end{array}$ & 572 & 876 & 701 & 1,625 & 3,775 \\
$\begin{array}{l}\text { Cost of } 1998 \text { output at } \\
1998 \text { prices }\end{array}$ & 102 & 811 & 902 & 1,966 & 3,781 \\
\begin{tabular}{l} 
Difference \\
\hline
\end{tabular} & 470 & 65 & -200 & -341 & -7 \\
\hline
\end{tabular}

Source: Author's calculations based on data from Bureau of Economic Analysis, National Income and Product Accounts. a. Normalized by the Divisia index of input.

b. For capital, 1998 dollars per 1998 dollar of capital; for labor, $1998=1.0$.

cost-of-adjustment parameter for e-capital, $\alpha^{e}$; the deterioration rate for e-capital, $\delta^{e}$; the rate of productivity growth for making e-capital, $\lambda$; and the annual rate $\rho$ at which Tobin's $q$ returns toward its normal level of one. Table 4 shows the result of doubling and of halving each of these parameter values while holding the others at their initial level. In all cases where the parameter is doubled, the change violates one of the above three criteria. All doublings except that of $\alpha^{k}$ drive productivity growth negative, and always by more than a trivial amount (ranging from -0.2 percent a year to -0.6 percent a year). All but the doubling of $\lambda$ cause a violation of the second WACM condition that the 1998 input bundle be cheaper at 1998 prices than the 1990 bundle.

Halving the adjustment cost for plant and equipment drives productivity growth negative, because it increases measured e-capital accumulation. Halving the rate of productivity growth for making e-capital causes a failure of the second WACM test, because e-capital is then not cheap enough 
Table 4. Sensitivity of Weak Axiom of Cost Minimization Tests to Parameter Selection

\begin{tabular}{|c|c|c|c|c|c|}
\hline Parameter & $\begin{array}{c}\text { Baseline } \\
\text { value }\end{array}$ & $\begin{array}{c}\text { Alternative } \\
\text { values }^{\mathrm{a}}\end{array}$ & $\begin{array}{c}\text { Is productivity } \\
\text { growth } \\
\text { nonnegative? }\end{array}$ & $\begin{array}{c}\text { Are } 1990 \\
\text { inputs cheaper } \\
\text { at } 1990 \\
\text { prices? }\end{array}$ & $\begin{array}{c}\text { Are } 1998 \\
\text { inputs cheaper } \\
\text { at } 1998 \\
\text { prices? }\end{array}$ \\
\hline \multirow[t]{2}{*}{$\alpha^{k}$} & 3.00 & 6.00 & Yes & Yes & No \\
\hline & & 1.50 & No & Yes & Yes \\
\hline \multirow[t]{2}{*}{$\alpha^{e}$} & 3.00 & 6.00 & No & Yes & No \\
\hline & & 1.50 & Yes & Yes & Yes \\
\hline \multirow[t]{2}{*}{$\delta^{e}$} & 0.06 & 0.12 & No & Yes & No \\
\hline & & 0.03 & Yes & Yes & Yes \\
\hline \multirow[t]{2}{*}{$\lambda$} & 0.03 & 0.06 & No & Yes & Yes \\
\hline & & 0.02 & Yes & Yes & No \\
\hline \multirow[t]{2}{*}{$\rho$} & 0.20 & 0.40 & No & Yes & No \\
\hline & & 0.10 & Yes & Yes & Yes \\
\hline
\end{tabular}

Source: Author's calculations.

a. Alternative values are either double or half the baseline values.

in 1998 to comport with the large amount of e-capital in use. None of the perturbations causes a violation of the first WACM condition.

\section{Skill-Biased Technical Change}

Previous research on the combination of rising relative wages and rising relative employment levels of more-skilled or more-educated workers has gravitated toward the idea of skill-biased technical change. ${ }^{22}$ Other explanations - notably, rising competition from low-wage workers in other parts of the world-receive little support. The e-capital model developed in this paper is an extension of the idea of skill bias, not a replacement for it. If e-capital were not durable-if it were a standard intermediate product-the two-sector e-capital model could be rewritten as a one-sector model relating output of goods and services to inputs of primary factors.

The durability of e-capital improves the explanatory power of skillbiased technical change in two ways. First, it helps align observed rapid rates of wage growth for college graduates with low observed rates of total factor productivity growth. Accumulation of e-capital fills in the differ-

22. See Katz and Autor (1999). 
ence, as explained earlier. Second, the e-capital model accounts for the rise in the stock market, a factor not previously considered in the skill bias literature.

Consider the following technology:

$$
q=A f(x c, h),
$$

where $x$ is an index of c-worker-augmenting technical change and $A$ the index of Hicks-neutral technical change. The wage of c-workers per efficiency unit is $w^{c} / x$. The elasticity of substitution between c-workers and h-workers, $\sigma$, is given by

$$
\sigma=-\frac{\Delta \ln \left(\frac{x c}{h}\right)}{\Delta \ln \left(\frac{w^{c}}{x w^{h}}\right)} .
$$

Given a value for the elasticity, one can infer the bias in technical change from observable data according to

$$
\Delta \ln x=\frac{\sigma}{\sigma-1} \Delta \ln \frac{w^{c}}{w^{h}}+\frac{1}{\sigma-1} \Delta \ln \frac{c}{h} .
$$

Equation (17) reflects the well-known proposition that the bias of technical change is not defined when the elasticity of substitution is unity, as in the Cobb-Douglas technology. Notice that the bias would go in the wrong direction-contradicting the observed increase in relative wages and increase in relative employment rates for c-workers-if the elasticity of substitution were less than one. With an elasticity not too much higher than one, the bias will be a high multiple of the relative wage increase and of the relative employment increase.

Another restriction on an interpretation based on biased technical change is that it should not involve technical regress: both the index of c-worker augmentation, $x$, and the index of output augmentation, $A$, should rise over time. Equivalently, one could say that productivity growth of both kinds of labor must be positive. The Solow residual for this technology is $\Delta \ln A+s^{c} \Delta \ln x$, where $s^{c}$ is the share of c-workers. The condition for nonnegative output augmentation is that $\Delta \ln x$ not exceed the Solow residual divided by $s^{c}$. With productivity growth at a 0.9 percent annual rate and the share of c-workers at 33 percent (both from the lower panel of table 2), the condition is that the rate of growth of the skill bias not 
exceed 2.7 percent a year. Figure 8 shows the results of these calculations, with the elasticity of substitution on the horizontal axis.

The hypothesis of skill-biased technical change cannot be made internally consistent for any value of the elasticity of substitution, although high values of the elasticity bring the rate of skill bias close to the cutoff level. For example, if the elasticity of substitution between c-workers and h-workers is 4 , bias growth is about 3.9 percent a year, which would contribute growth of 1.3 percent a year in the Solow residual, well above the observed growth of 0.9 percent a year.

These calculations demonstrate that the hypothesis of growth in the skill bias of the technology has trouble explaining the striking fact that the relative wages of college-educated workers have risen despite rapid growth in their employment relative to workers without college. Again, the model developed earlier in this paper is an elaboration of the idea of skill bias. Rather than placing the skill bias directly in the single aggregate production function, the model considers the accumulation of e-capital.

The discussion based on the technology of equation (15) applies only to the case of two factors, where the elasticity of substitution is a property of the technology and cannot be negative. With more factors whose prices are changing over time, $\sigma$ in equation (16) can take on any value; it loses its connection with any property of the technology. In the three-factor case without e-capital, one could try to explain the movements of employment and wages through changes in physical capital. However, I am not aware that any explanation of events in the labor market in the 1990s and earlier has been offered along those lines. In the four-factor case with e-capital, the opportunities to explain the movement of relative wages and relative employment levels in the same direction are richer. In particular, if e-capital and c-workers are complements, then increases in the amount of e-capital will raise the marginal product of $\mathrm{c}$-workers and permit wages to move in the same direction as employment. The only restriction that production theory imposes on the movements of factors and their prices is the WACM, tested in the previous section.

\section{The Relation between Stock Market Value and Education by Industry}

It would be difficult to reproduce the results of this paper at the industry level. A primary obstacle is that many firms are active in several indus- 
Figure 8. Rate of Growth of Bias Favoring College Graduates as a Function of the Elasticity of Substitution ${ }^{a}$

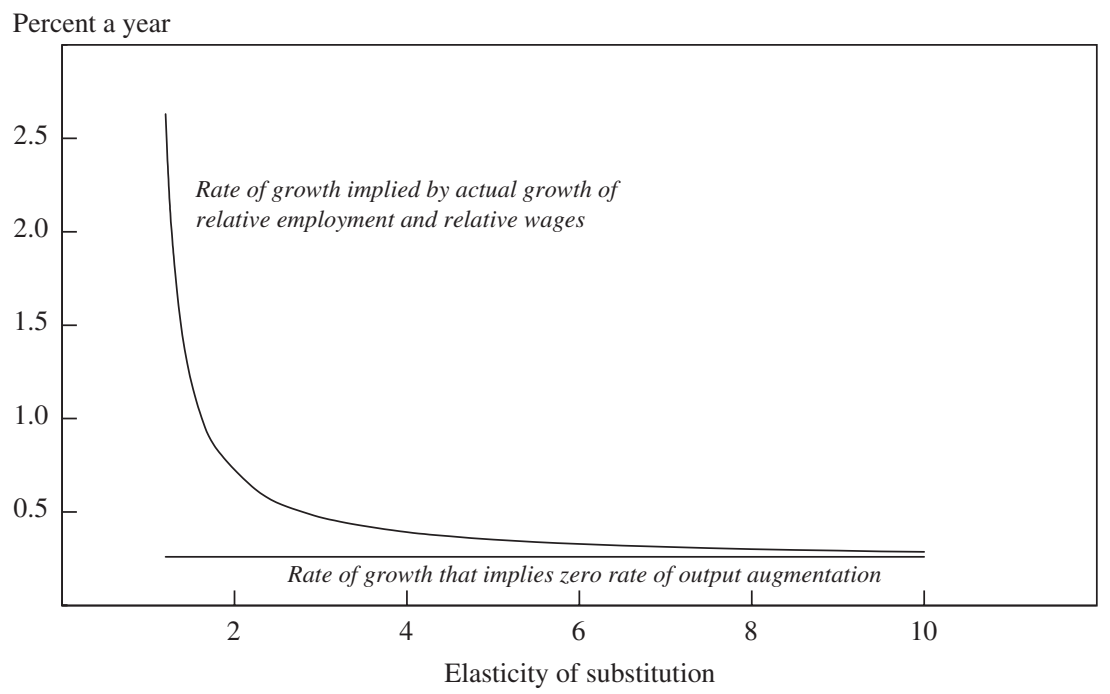

Source: Author's calculations. a. Over the period 1990-98.

tries, so that prices of their securities reflect the value of their activities in these various industries. Although data from Compustat can be compiled by industry, the resulting data are full of artifacts from movements of production units from one industry to another as the units change corporate ownership. Compustat also suffers from varying reporting rates over time for the stock of plant and equipment. It would be even more difficult to reproduce the results by firm, as data on education by firm are utterly lacking. Nonetheless, I have taken a look at the relation between securities values and work force education by industry.

Jason Cummins provided a tabulation of the firms in the Compustat database in 1998, from which I calculated a rough approximation to the value of their e-capital. I calculated a firm's e-capital as the market value of its equity plus the book value of its debt less the replacement value of its plant and equipment and the book values of its inventories and net cur- 
rent assets. This measure effectively assumes that $q^{k}$ and $q^{e}$ are both one, and so it ignores the effects of $q$ on valuation.

To measure the fraction of workers in each industry who have completed college, I tabulated the 1 percent public use sample of the 1990 Census of Population. I drew a sample of states, with sampling probabilities in proportion to population. Then I tabulated data for the 64,000 workers reported for the sampled states. The statistical sampling errors of the resulting estimated proportions of college graduates are close to zero.

For many industries there are gross discrepancies between the industry employment data reported in Compustat and employment reported in data based, like those of the census, on the industry of the employing establishment rather than the corporate owner. In a sample of industries where I judged that public corporations accounted for the bulk of employment, I found that employment reported by the Bureau of Labor Statistics (BLS) establishment survey was about 150 percent of Compustat employment. I rejected industries that fell outside a wide band around this value, from a ratio of 1 to a ratio of 4 . Thus I included industries where Compustat employment was between a quarter and all of BLS employment. In other industries the census data on the fraction of workers who had graduated from college would be dangerously irrelevant. Twenty-two industries at the two-digit classification level survived this cut.

Table 5 shows the results of these calculations. The data on the percentage of workers who have graduated from college contain few surprises. At the low end are food stores and low-technology manufacturing industries such as paper and steel. The industries where more than a quarter of workers are college graduates provide business and financial services. E-capital per worker is plainly positively related to college-graduate intensity. Figure 9 shows the relationship as a graph.

Regression of e-capital value on the number of workers with a college education produces a coefficient of $\$ 986,000$, with a standard error of $\$ 386,000$. This figure is more than double the average compensation for college-graduate workers over the eight-year period. Even with an allowance for the effect of $q^{e}$ of about a factor of 1.5 (see figure 6), the value of e-capital created per college-graduate worker exceeds the cost of employing the worker. But the most influential observations in table 5 are for financial services industries, where college graduates are paid more than in other industries, so the discrepancy may not be too great. 
Table 5. Share of Workers with a College Degree, 1990, and Estimated E-Capital per Worker, 1998, by Industry

Units as indicated

\begin{tabular}{|c|c|c|c|}
\hline $\begin{array}{l}\text { SIC } \\
\text { code }^{\mathrm{a}}\end{array}$ & Industry & $\begin{array}{l}\text { Workers with a } \\
\text { college degree } \\
\quad \text { (percent) }\end{array}$ & $\begin{array}{c}\text { E-capital per } \\
\text { worker (thousands } \\
\text { of } 1998 \text { dollars) }\end{array}$ \\
\hline 54 & Food stores & 7.0 & 26 \\
\hline 14 & Nonmetallic minerals, except fuels & 10.6 & 36 \\
\hline 26 & Paper and allied products & 10.6 & 139 \\
\hline 33 & Primary metal industries & 10.7 & 11 \\
\hline 34 & Fabricated metal products & 11.7 & 52 \\
\hline 53 & General merchandise stores & 12.3 & 41 \\
\hline 20 & Food and kindred products & 13.6 & 369 \\
\hline 13 & Oil and gas extraction & 13.7 & 65 \\
\hline 56 & Apparel and accessory stores & 15.9 & 21 \\
\hline 35 & Industrial machinery and equipment & 15.9 & 252 \\
\hline 59 & Miscellaneous retail & 19.2 & 42 \\
\hline 38 & Instruments and related products & 19.6 & 210 \\
\hline 49 & Electric, gas, and sanitary services & 19.9 & 161 \\
\hline 48 & Communication & 20.8 & 736 \\
\hline 78 & Motion pictures & 21.5 & 230 \\
\hline 45 & Transportation by air & 23.4 & -23 \\
\hline 27 & Printing and publishing & 23.5 & 124 \\
\hline 73 & Business services & 26.0 & 192 \\
\hline 60 & Depository institutions & 26.3 & 978 \\
\hline 63 & Insurance carriers & 32.4 & 455 \\
\hline 61 & Nondepository financial institutions & 43.9 & 3,450 \\
\hline 62 & Security and commodities brokers & 57.6 & 558 \\
\hline
\end{tabular}

Source: Author's calculations based on data from Bureau of Economic Analysis, National Income and Product Accounts; and Jason Cummins, New York University.

a. U.S. Standard Industrial Classification system.

These results across industries provide rough confirmation of the view that college graduates - makers of e-capital - tended to be employed in those industries where e-capital, in the view of the stock market, was actually being made. Many of these college-graduate-intensive, highe-capital industries - notably engineering and management services-are also computer-intensive industries. These results add to Jorgenson and Kevin Stiroh's evidence that the negative values of productivity growth in computer-using industries are probably the result of errors in the price data. $^{23}$ 
Figure 9. E-Capital per Worker and Work Force Share of College Graduates by Industry, 1998

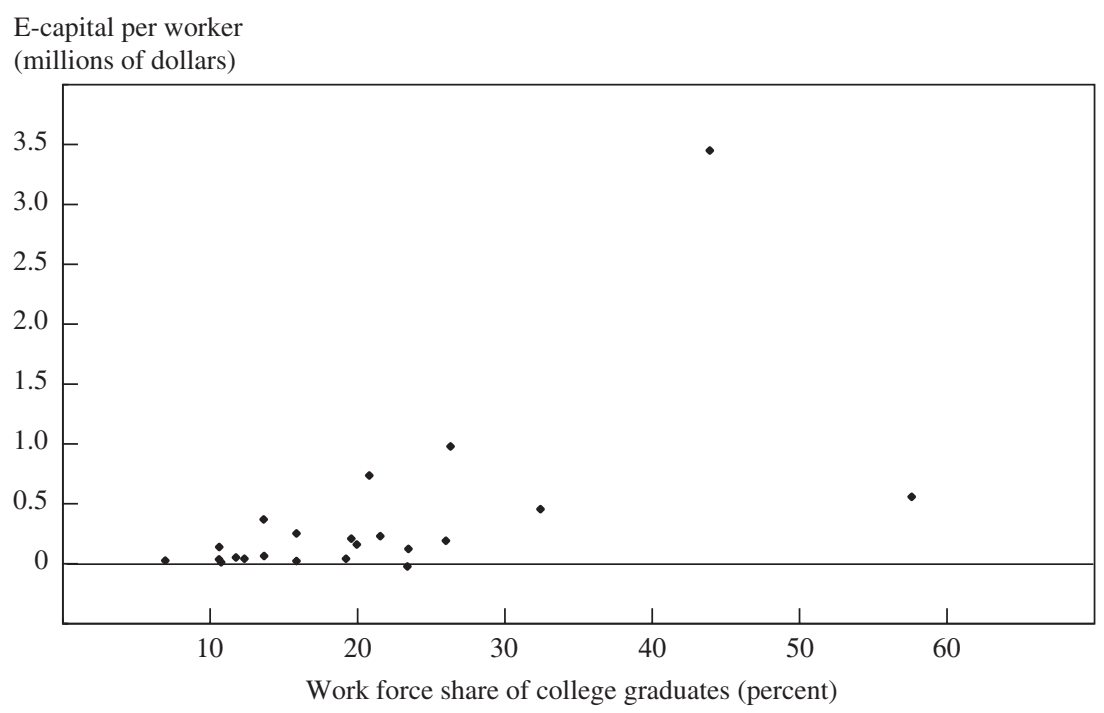

Source: Author's calculations based on data from Bureau of the Census, Current Population Survey; and Jason Cummins, New York University.

\section{Concluding Remarks}

The 1990s saw two remarkable changes in the U.S. economy. One was the huge increase in the stock market. The other was the rapid growth in the earnings of college graduates even as these workers came to account for a substantially larger fraction of the labor force. The natural explanations for these phenomena invoke productivity growth. But growth of recorded productivity over the decade was only a little above that in the two preceding decades and well below that in the 1950s and 1960s. Nor can skill-biased technical change by itself explain the relative earnings and employment levels of college graduates, because of the relatively low level of total factor productivity growth.

This paper has developed a view that is consistent with all of these facts. But it is not yet compelled by these facts. We may learn in coming years (for example, through a stock market crash) that the high stock market valuations were a mistake and that corporations had not accumulated capital 
of corresponding value. And skill bias could be a contributor to, if not the full explanation of, the sharp growth in the relative earnings of college graduates.

Nonetheless, I find it more satisfactory to link the two phenomena through the concept of e-capital. This theory replaces the twist of the production function implicit in the skill bias view with a new factor of production. It is the comparative advantage of college graduates in making e-capital, together with the willingness of U.S. residents and foreigners to finance huge amounts of e-capital, that has driven up their wages, not an arbitrary change in the production function. 


\section{Comments and Discussion}

Jason G. Cummins: This is one of the most ambitious papers that I have ever read. Robert Hall proposes a unified explanation for two of the preeminent economic events in the United States in the last ten years: the extraordinary rise of the stock market and the increase in the skill premium to college-educated workers. His explanation is that intangible capital, which is used predominantly by college graduates, grew at an extraordinary pace in the 1990s. Hence the stock market boom simply reflects the market value of this intangible capital, and the rise in relative earnings reflects the increased demand for college graduates.

Intangible capital, as it is typically defined, consists of assets such as patents, copyrights, trademarks, formulas, and brand names. These assets are built by investment in advertising and in research and development (R\&D). But Hall does not argue that the growth of these types of intangibles is responsible for the stock market boom or the growing wage gap. Indeed, one quickly realizes why: investment in advertising and $R \& D$, however broadly measured, has not increased nearly enough to explain these two events. Nakamura reports that advertising as a proportion of nonfinancial corporate gross domestic profit grew from 3.9 percent in the period 1980-89 to 4.1 percent in 1990-97. ${ }^{1}$ The comparable figures for R\&D are 2.3 percent in 1980-89 and 2.9 percent in 1990-97. Instead, Hall introduces another type of intangible asset: e-capital, which is the body of technical and organizational know-how created by college graduates using computers and software. The idea that computers and software are 
used to create important assets that are unrecorded in company and national accounts is not new. ${ }^{2}$ The catchy name, however, is.

Unfortunately, nobody really knows what this technical and organizational know-how consists of. One might think that this would be a rather substantial obstacle to studying e-capital. But Hall has an ingenious workaround. He shows that, under certain assumptions, e-capital can be defined in a purely mechanical way, which obviates the need to say exactly what it is. Some readers might object that this type of approach is obscurantist. However, this would be misguided, because Hall is very clear about what his goals are and, perhaps more important, what his goals are not.

To understand the contribution of this study, it is important to elaborate on this point. In particular, Hall's goal is not to test whether e-capital is the link between the stock market and the labor market in the 1990s. Rather, his goal is to show that e-capital could be the link. Of course, there is a difference between arguing that there is a way to fashion the e-capital story so that it is not inconsistent with the data and arguing that the data compel that story. Hall acknowledges this stricture, but my biggest concern is that it will go unrecognized by those who read the paper carelessly.

In my view, the careful reader will see that this paper is a contribution to aesthetics as much as anything else: Hall has found a way to rationalize two phenomena that he thinks is "more satisfactory" than other possibilities. Whether Hall's aesthetic conception persuades the reader depends on three things. First, it depends on whether the assumptions necessary to make the e-capital story work are realistic. Second, it depends on whether the story is robust to changes in the way the model is calibrated. Finally, it depends on whether the story is sufficiently rich to explain the data. The paper falls short in all three respects. Nevertheless, Hall has established a useful benchmark for further research. My own view is that intangible capital will be an important ingredient in the compelling explanation that does eventually emerge for the recent behavior of the U.S. stock and labor markets. But it will not be the sole explanation as Hall argues. I discuss below the other ingredients needed in the $\operatorname{mix}$.

2. For a survey see Lev (2000). 
Hall marshals four key sets of assumptions to derive e-capital. The first is that firms operate in perfectly competitive markets with a constantreturns-to-scale (CRS) production technology that uses e-capital among other factors of production. The second is that the adjustment cost technology for e-capital is a linear-quadratic function scaled by the quantity of property, plant, and equipment (PPE). The third is that the rental price of e-capital depends on the ratio $q^{e}$ of the price of installed e-capital to the price of new e-capital, on the rate $\rho$ at which $q^{e}$ returns to its equilibrium value of unity, and on the wage $p^{e}$ of college graduates measured in efficiency units. And the fourth is that the stock market is strongly efficient in the sense that equity prices just equal the value of all of the firm's productive assets, tangible and intangible. If these assumptions are satisfied, the value of e-capital can be calculated as the difference between the value of the stock market and the value of PPE. The quantity of e-capital can then be inferred as the value of e-capital divided by $p^{e} q^{e}$.

I assess these assumptions by thinking about whether they truly describe the companies that Hall cites as intensive in e-capital, such as Yahoo! Inc. and Wal-Mart Stores, Inc. Does his first set of assumptions, that these companies are perfectly competitive with CRS production technologies, make sense? To be fair, these assumptions need to hold only approximately, but they appear not to hold even approximately for the types of companies that Hall has in mind.

Yahoo! indeed has many competitors, and so the assumption of perfect competition is not wide of the mark. The assumption of CRS, on the other hand, is not as innocuous as it may seem. Yahoo!'s e-capital comes from the way its computers and software organize and deliver information. It is difficult even to think about what it might mean to double this factor of production because it is essentially indivisible. CRS may not be as bad an approximation for Wal-Mart, but a key part of its business model is to build stores in areas where markups can be sustained, and this would seem to violate the perfect competition assumption. Hall does not mention Microsoft, perhaps the premier e-capital-intensive company. Recently, however, he himself has argued that Microsoft violates the assumptions on which his model depends: in a recent unpublished paper he calculates that Microsoft's market power has cost consumers billions of dollars. ${ }^{3}$ If

3. Hall and Hall (2000). Hall (1988) casts his net wider and finds that there were significant markups in a number of industries. 
CRS and perfect competition are violated in these ways, the value Hall attributes to e-capital is overstated.

This discussion of the production technology points up the thornier issue of how to model e-capital. One way to think about e-capital is as a nexus of business methods based on information technology. It is clear that there has been an explosion of such methods, with Yahoo! just one of many outstanding examples. But Hall treats e-capital very much like any other quasi-fixed factor of production. Firms buy it just like they buy staplers. Granted, in Hall's model college graduates are needed to create e-capital, whereas physical capital is purchased from suppliers. But e-capital does not work like this. If Hall and I wanted to start up a dot-com company, we could not simply replicate Yahoo!'s e-capital by hiring some college graduates. That is because Yahoo!'s e-capital is a distinct way of combining the usual factors of production, not an input itself.

To formalize this conception of e-capital, I would begin by expressing the production technology as

$$
q_{t}=A_{t} f_{i}\left(k_{t}, c_{t}, h_{t}, m_{t}\right),
$$

where $A$ is an index of Hicks-neutral technical change, $k$ is the quantity of physical capital in efficiency units, $c$ is the labor input of college graduates, $h$ is the labor input of other workers, and $m$ is materials. The key difference between this formulation and Hall's equation (1) is that the production technology, $f$, depends on e-capital through the index $i$. This captures the idea that the output of Yahoo! and, say, Lycos may differ even though they utilize the same factors of production. It also clarifies why it makes no sense to ask what are e-capital's returns to scale and elasticities of substitution, and why perfect competition may be such a poor approximation. My formulation is strictly more general than the one Hall adopts, and so there may be a sensible way to go from mine to his. But that remains an important open question. The reader can certainly imagine other technological specifications that are as compelling as Hall's.

The second set of assumptions concerns the adjustment cost technology for e-capital. It is linear-quadratic with a constant deterioration rate. There is essentially no evidence to support or to refute this choice, perhaps because, again, e-capital is not really a quasi-fixed factor like PPE. With that important caveat in mind, the standard linear-quadratic model is a sensible place to start, especially given that research has been inconclusive 
about whether such a specification is inappropriate for PPE. Given our ignorance, this would also be a good area in which to focus future research.

The peculiar feature of Hall's adjustment cost technology is that it depends inversely on the quantity of PPE. Firms that have the greatest total and marginal adjustment costs for e-capital investments of the same size are those with relatively little PPE. So Hall cannot really have companies like Yahoo! in mind when he talks about e-capital producers. Total and marginal adjustment costs would approach infinity for firms with very little PPE like Yahoo! Conversely, firms like General Motors would have tiny adjustment costs because their stock of PPE is so large. This setup is backwards. If it were valid, we would have been reading throughout the 1990s about gm.com, not Yahoo!

The third set of assumptions involves the rental price of installed e-capital. Part of my concern about the calculation of the rental price stems from the assumptions about the production and adjustment cost technologies that I have already highlighted. The rental price depends on the wage of college graduates in efficiency units, $p^{e}$, and on $q^{e}$. Both of these embody a particular conception of e-capital. First, e-capital can be purchased like any other quasi-fixed input by hiring college graduates. And second, e-capital is cheaper for firms with large stocks of PPE.

The remainder of my concern about the rental price is that expectations are treated haphazardly. Firms are assumed to have perfect foresight about the future price of uninstalled e-capital. Yet this, for the purposes of the computations, amounts to assuming that they knew in 1990 the wage that college graduates would earn in 1999. Moreover, the rate at which $q^{e}$ returns to its equilibrium value of unity, $\rho$, is determined outside the model. The latter point also applies to the rental price of PPE since $\rho$ enters in the same way.

Hall's final assumption is that the stock market is strongly efficient. Most readers of this volume will not have followed the evolution of this paper, and thus will be unaware of perhaps the most piquant evidence against this assumption, namely, the fact that Hall has had to continually revise downward the market capitalization of Yahoo! cited in his first paragraph. When the paper was first written, in May of 2000, Yahoo!'s market capitalization was over $\$ 120$ billion. By the time the paper was presented to the Brookings Panel in September, it had dropped to about $\$ 72$ billion. As I write this comment it has again fallen by about 50 percent, to $\$ 37$ bil- 
lion. These changes are not necessarily inconsistent with strong efficiency-Yahoo!'s market capitalization could reflect changes in expected profits or expected returns, or both. But the fall does illustrate a potential pitfall to Hall's approach. If equity prices faithfully reflect the value of a firm's e-capital, Yahoo! has destroyed an enormous amount of e-capital in the last six months.

It is possible that there was a bubble in Yahoo!'s share price and, more generally, in the share prices of companies that are e-capital-intensive. There are, in fact, a wide variety of other reasons why asset prices may not reflect fundamentals; some are consistent with weaker forms of market efficiency, and some are not. But the important point is that the presence of these reasons would lead Hall to overstate the value of e-capital by the size of the mismeasurement.

This is easy to illustrate using a variant of Hall's model. The fundamental value of the firm $V_{t}^{*}$ is equal to the sum of the value of PPE and the value of e-capital: $V_{t}^{*}=q_{t}^{k} k_{t}+q_{t}^{e} e_{t}$. Suppose that the firm's stock market value $V_{t}^{E}$ differs from its fundamental value by $m_{t}$, perhaps because of a bubble. In this case, $V_{t}^{E}=V_{t}^{*}+m_{t}$. When the stock market value of the firm is substituted for the unobservable fundamental value of the firm, the result is $V_{t}^{E}=q_{t}^{k} k_{t}+q_{t}^{e} e_{t}+m_{t}$. Hence, Hall's decomposition yields $q_{t}^{e} e_{t}+m_{t}$ as the value of e-capital instead of $q_{t}^{e} e_{t}$.

Based on these four sets of assumptions, Hall then develops a twopronged empirical approach. In the first part of this investigation, Hall chooses technological parameters for which it is logically possible that e-capital does not violate the weak axiom of cost minimization (WACM). He shows, however, that the results are sensitive to parameters that are arguably as reasonable as the ones he chooses. In particular, total factor productivity is negative, and the WACM test for 1998 is rejected, for most alternative parameter values. In the second part of the empirical work, Hall shows that college graduates populate the industries that are e-capitalintensive. This is reassuring, since it seems to be a necessary condition for e-capital to lead to an increase in the skill premium.

Finally, the question remains whether the e-capital story is sufficiently rich to explain the data. At a basic level we know that it is not, because e-capital is negative for firms whose stock market value is less than the value of their PPE. In essence, this means that, if we ignore adjustment costs, e-capital is negative for firms with values of Tobin's $q$ that are less than unity. And there are many such firms. Indeed, the median firm had 
negative e-capital from 1980 to 1987 in the sample of firms used by Stephen Bond and myself. ${ }^{4}$ It is hard to believe that the 1980 s were predominantly a time when e-capital destroyed value. But this is what one has to believe if one thinks that the 1990 s were predominantly a time when e-capital generated value.

A similar problem is that the increase in college graduates' earnings relative to those of non-college graduates did not start in 1990. It started in the early 1980s and continued in the 1990s. But e-capital cannot explain the emergence of the skill premium because it was, by and large, negative in the 1980s. So e-capital is, at best, only a partial explanation.

Hall is led into these apparent contradictions because the e-capital story is unnecessarily restrictive. There may be periods when the stock market deviates from fundamentals. In addition, there are other factors of production that complement college graduates. Recent research suggests ways to generalize Hall's model along these two lines. Bond and Cummins introduce a less restrictive model, incorporating both market mispricing and a role for intangible capital. ${ }^{5}$ They find that intangible capital cannot rationalize the runup in the stock market from 1982 to 1998. Per Krusell and others show that complementarity of tangible capital and skill explains the movements of the skill premium from the mid-1960s to the early 1990s. ${ }^{6}$

In summary, I would stress that it is always appealing to look to unobservables, like e-capital, to explain apparent paradoxes or anomalies. To have any degree of confidence in this type of explanation, however, one has to exploit the testable implications of the dynamic stochastic structure of the unobservables (as, for example, Bond and Cummins have done). ${ }^{7}$ Until we have a more complete set of these types of results, Hall's provocative findings will be interpreted in a variety of ways, depending on the reader's bias. To new economy skeptics, they may serve as a sort of reductio ad absurdum, whereas for the arguments of new economy enthusiasts they may prove to be the cornerstone. In any case, the lasting contribution of this study is that it shows that capital accumulation, broadly conceived, has the potential to rationalize important and seemingly disparate phenomena. Even if Hall falls short of his goal to provide a

4. Bond and Cummins (2000).

5. Bond and Cummins (2000).

6. Krusell and others (2000).

7. Bond and Cummins (2000). 
grand unified theory of the rise in the stock market and the skill premium in the 1990s, his approach points the way for how to integrate features of the new economy into a coherent economic model.

Owen A. Lamont: As usual, Robert Hall has produced a provocative paper that deftly combines wide-ranging types of evidence and an appealing theory. I think we can all agree that the ingredients of the story-a high stock market, new technology, slow apparent productivity growth, high wages for skilled workers-are both individually and collectively fascinating and must be related somehow.

Hall's figure 7 is certainly a thought-provoking picture. It breaks down the value of the stock market into two components, the value of physical capital and a residual. The value of physical capital is the cost of physical capital plus the difference between value and cost. To arrive at this additional value over cost, it is necessary to estimate Tobin's $q$ for physical capital. The traditional estimate of $q$ involves using the market value, but since Hall wants to save that variable for other uses, he instead infers $q$ from the quantity of investment in physical capital. Under constant returns to scale with quadratic investment costs, $q$ is just a function of the adjustment cost parameter and the growth of physical capital. Thus the fact that figure 7 shows only a modest role for physical capital reflects both the low quantity of physical capital relative to market value and its relatively smooth, slow adjustment (as well as Hall's guess as to the value of the adjustment parameter).

Although ingenious, this method is not without problems. The main problem is that investment regressions using $q$ do not work very well, even when one uses data from before 1990, when e-capital presumably did not exist. So inferring $q$ from investment seems likely to produce unreliable estimates of the value of physical capital. Continuing with figure 7, Hall estimates the value of e-capital as the difference between actual stock market value and the imputed value of physical capital. But if the estimates of the imputed value of physical capital are unreliable, it follows that the estimates of e-capital are also unreliable.

An example may be helpful. As Stephen Bond and Jason Cummins reported in the last issue of the Brookings Papers, the Coca-Cola Company had a $q$ of more than 5 in the late 1980s. ${ }^{1}$ Assuming, as Hall does, that 
there was no e-capital then, according to the model that assumes quadratic adjustment costs with constant returns to scale, Coca-Cola should have been madly adding physical capital in order to produce more output (and driving its $q$ back toward one). It did not, and we all know why: constant-returns-to-scale technology with competitive output markets is a terrible description of Coca-Cola's actual situation.

This example leads me to an important question: what exactly is e-capital? As calculated by Hall, it seems as if e-capital is all nonphysical assets owned by the corporation. Yet the paper's calculations assume that e-capital is zero prior to 1990. It seems odd to assume that nonphysical assets (brand names, advertising, patents, secret formulas, marketing networks, and so on) did not exist prior to 1990 . Surely throughout the twentieth century many firms in the services industry (such as advertising, legal, accounting, consulting, and financial services) have had relatively small amounts of physical capital.

The pre-1990 evidence is fairly compelling on one point: the ratio of market value to the cost of physical capital (Tobin's $q$ ) varies a lot. Olivier Blanchard, Changyong Rhee, and Lawrence Summers, for example, found that $q$ varies wildly, from a low of 0.39 in 1920 to a high of 1.28 in 1936, and ending, in their series, at 0.9 in $1990 .{ }^{2}$ So it is no more than happenstance that $q$ was around 1 in 1990, where Hall's figure 7 begins.

The paper mentions the puzzle of low stock market valuations in the 1970s and 1980s. An explanation related to e-capital is provided by Jeremy Greenwood and Boyan Jovanovic, who theorize that much of the technology revolution was already foreseeable in the early 1970s. ${ }^{3}$ In their view, expectations about the impact of technology caused the decline in the stock market, as the market expected existing firms to be driven out by new firms. These new firms, such as Microsoft, did not yet exist and thus were not traded, and so their values were not yet reflected in the market.

Another factor contributing to the fluctuation in $q$ is variance in expected returns on stocks over time. Expected returns can vary for either rational reasons (perhaps changes in risk, changes in risk aversion, or changes in risk sharing) or irrational reasons (overpricing and underpricing). Although there is no consensus on why expected returns vary, there is

2. Blanchard, Rhee, and Summers (1993).

3. Greenwood and Jovanovic (2000). 
a moderately strong consensus, based on moderately strong time-series evidence, that they do vary. They are not constant.

It is true, indeed tautological, that the value of any security is due to future cash flows to holders of the security and future rates of return on the security. Thus today's high market value mechanically implies either that future cash flows are high, or that future returns are low, or some combination of the two. Using a similar mechanical relation, Tuomo Vuolteenaho shows that the ratio of market value to book value, which is roughly equal to Tobin's $q$, is a function of future returns on the security in question and of future corporate profits. ${ }^{4} \mathrm{He}$ decomposes the variance of the aggregate market value-book value ratio over the period 1871-1999 and finds that almost all the time-series variation is due to variation in expected returns, not in expected profits. This result is an important contradiction of the idea that intangible assets are responsible for variation in $q$. If these intangible assets are valuable, they should generate corporate profits in the future. But Vuolteenaho finds that high levels of inferred intangible assets do not predict future profitability.

Thus one possibility is that $q$ is high because future returns are low. Indeed, this possibility seemed plausible in 1998 to Hall himself. A paraphrase of his remarks at a Brookings Panel discussion that year begins as follows: "If stock market wealth rises due to a decrease in the discount rate rather than an increase in profit flows, as appears to be the case today...." Now, as the Hall of 2000 rightly points out, the different ways of characterizing firm value should be the same in equilibrium. Future discounted cash flows to security holders should be equal to the value of firm assets. Under standard assumptions, if the discount rate is low today, firms should respond by investing more in physical capital. And there is some evidence that firms do change their investment in response to changes in expected risk premiums on their stocks. ${ }^{6}$

But again, we go back to the quantitative failure of the standard model to explain investment. Although constant returns to scale with quadratic adjustment is certainly a useful model for thinking about and describing reality, it is far from a complete description. Hence I am not terribly surprised that the standard model is unable to account for the seeming underinvestment in physical capital. There is a lot of truth in the standard model;

4. Vuolteenaho (1999).

5. BPEA 1:1998, p. 333.

6. Cochrane (1991); Lamont (2000). 
as Hall's figure 7 demonstrates, there was a substantial investment boom in the 1990s. Especially in the late 1990s, firms issued equity and invested, just as they should in response to high market values. Under many different scenarios, including both rationally low discount rates and irrationally high prices, firms should increase investment when the stock market goes up. The failure of the standard model is not in the qualitative prediction about aggregate investment, which is surely right, but in the quantitative prediction, which is somewhat off.

The highest honor that economics can bestow is to name an equation, parameter, model, or residual after its inventor. So let me propose a more descriptive name for the object that the paper calls e-capital. I propose we call it "Hall's residual." There is a lot of truth to the idea that Hall's residual captures important assets that do not appear on the balance sheet, and Hall presents a useful framework for quantifying the inputs and value of these assets. These intangible assets, including "electronic" intangibles but also advertising, patents, and so on, are captured in the residual. But like all residuals, Hall's residual contains a diverse collection of factors that we will never fully understand. The paper goes beyond just identifying a residual, of course, to nicely tie together the residual with other evidence on wages and productivity. But it is important to remember that Hall's residual is a residual, and as such captures all departures from constant returns and quadratic adjustment costs.

The paper mentions Yahoo! Inc. as a motivating example. The recent valuation of technology stocks is indeed a puzzle. I will therefore conclude with a specific example of mispricing of technology stocks. In calculating Hall's residual, the paper adopts the principle that the value of the stock market equals the value of its component assets. This idea is extremely important in financial economics, especially when the various components are themselves tradable. It has various names, such as the no-arbitrage principle and the law of one price. Arbitrage, defined as the simultaneous buying and selling of the same asset for two different prices, is the basis of almost all modern financial theory, including the theories of option pricing and corporate capital structure.

The example, from my own work with Richard Thaler, ${ }^{7}$ suggests that understanding current market valuations is peculiarly difficult. In March 2000, 3Com Corp. sold about 5 percent of its stake in Palm, Inc., to the

\footnotetext{
7. Lamont and Thaler (2000).
} 
general public, while retaining the rest. On the first day of trading, Palm immediately went from the issue price of $\$ 38$ a share to $\$ 145$ a share, and later rose as high as $\$ 165$, before ending the day at $\$ 95$ (all prices rounded to the nearest dollar). Given the relative number of shares outstanding of Palm and 3Com, a holder of one share of 3Com stock indirectly owned 1.5 shares of Palm stock. Thus, based on 3Com's ownership of Palm alone, at the end of the first day of trading, 3Com shares were worth at least \$143. Yet 3Com's actual value at the end of trading that day was $\$ 82$ (in fact, 3Com's stock price fell 21 percent that day from its previous close).

The "stub value," or implied value of 3Com's non-Palm assets and businesses, is the difference between the lower bound of $\$ 143$ and the observed price of $\$ 82$, or $-\$ 61$. For some reason, the market implicitly assigned a negative value to 3Com's other assets. Most puzzling of all, 3 Com had publicly announced its intention to spin off its remaining shares of Palm by the end of the year. Thus, in order to profit from the mispricing, an arbitrageur would have needed simply to buy shares of $3 \mathrm{Com}$, short 1.5 times that many shares of Palm, and wait less than a year. This apparent near-arbitrage opportunity was not easily exploitable, however, because of the difficulty of shorting Palm.

Using the observed value of 3Com's assets, Hall's residual for 3Com on this date would have been massively negative. Obviously, this example is a bit unfair since Hall's approach is designed to explain aggregate facts, not the prices of specific stocks. But it suggests that our cherished principles of value additivity may have broken down in the late 1990s. This example suggests to me that Hall's residual may contain a lot of ugly ingredients, perhaps including mispricing.

General discussion: Several panelists were skeptical of the two central assumptions of Hall's analysis: that the market value of physical capital can be accurately inferred by simply plugging actual investment in plant and equipment into an inverted $q$ investment equation, and that the difference between Hall's implied market value of physical capital and the market's valuation of firms should be entirely attributed to e-capital. Gregory Mankiw observed that there is a large literature rejecting $q$ theory. Although Hall provided a rationalization for the apparent failure of the theory in the 1990s, the theory did not perform well empirically in the preceding thirty years either, when, according to Hall, e-capital was not distorting the measurement of firms' capital. Hence Mankiw warned against 
taking Hall's estimates of e-capital too seriously. Edward Glaeser agreed with this skepticism but suggested that Hall's basic insight, that investment would be much greater if market values reflected only physical capital, was correct. Both Mankiw and Glaeser felt that what Hall attributed solely to e-capital should be attributed to intangibles more generally. Mankiw proposed running Hall's equations backward in time, with the possibility of clarifying whether the technological revolution associated with electronic devices (as implied by the lowercase "e") was behind the phenomena described or whether it is instead due to broader effects of intangible capital. William Brainard observed that, unless Hall's theory were modified in some way, his equations would have difficulty during much of the earlier period, when the quantity of e-capital or intangibles implied by his procedure would be negative, since investment in physical capital was positive and the market value of firms was below the replacement cost of physical capital alone. Hall agreed that the apparatus proposed in the paper does not give intelligible answers to what was observed during the 1970s.

Matthew Shapiro was sympathetic to the view that current high market values reflect, at least in part, increased importance of intangibles. $\mathrm{He}$ observed that information technology firms are similar to drug companies, in which a large fraction of workers are paid for the discovery and development of drugs, and market values reflect the market's estimate of returns to these innovations rather than the returns to physical capital. Such firms are not appropriately described by conventional models with constant returns to scale in production and competitive pricing. Information technology products, like drugs, have high fixed costs and low marginal costs; profits from the successful products are quasi-rents, not returns to physical capital. Glaeser wondered whether such a large fraction of the returns to intellectual innovations could be going to the firms rather than to the c-workers who produce the innovations. Pierre-Olivier Gourinchas observed that Hall's story has trouble explaining the slowdown in the growth of wage inequality between skilled and unskilled workers in recent years. According to the e-capital story, one would have expected inequality to have increased even faster in the second half of the 1990s than in earlier periods.

Daniel Sichel raised a question about the magnitude of Hall's estimates of e-capital, since they imply that growth in multifactor productivity (MFP) was very slow during the 1990s. He believed that technical progress, particularly in semiconductors and computers, had been quite 
rapid; if one accepted Dale Jorgenson and Kevin Stiroh's estimates of overall MFP growth, Hall's estimates of e-capital almost surely imply significantly negative MFP growth outside those sectors. Sichel wondered whether Hall's framework allocated such technological improvement to the accumulation of e-capital. Gourinchas observed that technological innovations might have occurred well before they showed up in productivity improvements. He noted that it normally takes time for ideas to be embodied in commercial applications, and it is easy to see why in the case of information technology, where network externalities are likely to be important, the lags would be especially long. Robert Gordon said he would be more persuaded by the analysis if Hall could show that the formation of e-capital by c-labor did a good job of explaining the valuation of e-capital firms relative to other firms. Given the current market valuations of e-capital firms, he also wondered whether the amount of c-labor required to produce the estimated e-capital for those firms greatly exceeded actual employment. 


\section{References}

Abel, Andrew. 1979. Investment and the Value of Capital. New York: Garland. . 1999. "The Effects of a Baby Boom on Stock Prices and Capital Accumulation in the Presence of Social Security." Unpublished paper. Wharton School of Business, University of Pennsylvania (October).

Blanchard, Olivier, Changyong Rhee, and Lawrence Summers. 1993. "The Stock Market, Profit, and Investment." Quarterly Journal of Economics 108(1): 115-36.

Bond, Stephen R., and Jason G. Cummins. 2000. "The Stock Market and Investment in the New Economy: Some Tangible Facts and Intangible Fictions." BPEA, 1:2000, 61-108.

Brainard, William C., John B. Shoven, and Laurence Weiss. 1980. "The Financial Valuation of the Return to Capital." BPEA, 2:1980, 453-502.

Brynjolfsson, Erik, and Shinkyu Yang. 1999. "The Intangible Costs and Benefits of Computer Investments: Evidence from the Financial Markets.” Sloan School of Management, Massachusetts Institute of Technology (April).

Cochrane, John H. 1991. "Production-Based Asset Pricing and the Link between Stock Returns and Economic Fluctuations." Journal of Finance 46(1): 209-37.

Greenwood, Jeremy, and Boyan Jovanovic. 1999. "The Information-Technology Revolution and the Stock Market.” American Economic Review 89(2): 116-22.

Hall, Robert E. 1988. "The Relation between Price and Marginal Cost in U.S. Industries." Journal of Political Economy 96(2): 339-57.

___ 1990. "Invariance Properties of Solow's Productivity Residual." In Growth, Productivity, Unemployment: Essays to Celebrate Bob Solow's Birthday, edited by Peter Diamond. MIT Press.

_. 2000. "The Stock Market and Capital Accumulation." Unpublished paper. Hoover Institution, Stanford University (May). (Available at www.stanford.edu/ $\sim$ rehall/page2.html)

Hall, Chris E., and Robert E. Hall. 2000. "Toward a Quantification of the Effects of Microsoft's Conduct.” American Economic Review 90(2): 188-91.

Hall, Robert E., and Dale W. Jorgenson. 1967. "Tax Policy and Investment Behavior." American Economic Review 57(3): 391-414.

Jorgenson, Dale W., and Kevin J. Stiroh. 2000. "Raising the Speed Limit: U.S. Economic Growth in the Information Age." BPEA, 1:2000, 125-211.

Katz, Lawrence F., and David H. Autor. 1999. "Changes in the Wage Structure and Earnings Inequality." In Handbook of Labor Economics, vol. 3A, edited by Orley Ashenfelter and David Card. New York: North Holland.

Krusell, Per, and others. 2000. "Capital-Skill Complementarity and Inequality: A Macroeconomic Analysis." Econometrica 68(5): 1029-53.

Lamont, Owen A. 2000. "Investment Plans and Stock Returns." Journal of Finance 55(6): 2719-45. 
Lamont, Owen A., and Richard H. Thaler. 2000. "Can the Market Add and Subtract? Mispricing in Tech Stock Carve-Outs." Unpublished paper. Graduate School of Business, University of Chicago (October). (Available at www.gsb. uchicago.edu/fac/owen.lamont/research/wp.html)

Lev, Baruch. 2000. "Intangibles: Management, Measurement, and Reporting." Unpublished paper. New York University (October).

Nakamura, Leonard. 1999. "Intangibles: What Put the New in the New Economy?" Federal Reserve Bank of Philadelphia Business Review, July/August, pp. 3-16.

Star, Spencer, and Robert E. Hall. 1976. "An Approximate Divisia Index of Total Factor Productivity.” Econometrica 44(2): 257-63.

Varian, Hal R. 1984. "The Nonparametric Approach to Production Analysis." Econometrica 52(3): 579-98.

Vuolteenaho, Tuomooskari. 1999. "Understanding the Aggregate Book-to-Market Ratio.” Working paper. New York: Social Science Research Network (May). 